\title{
Improving usability and maintaining performance: human-factor and aerosol-performance studies evaluating the new reusable Respimat inhaler
}

This article was published in the following Dove Medical Press journal: International Journal of COPD

Rajiv Dhand,' Joachim Eicher, ${ }^{2}$ Michaela Hänsel, ${ }^{3}$ Ingeborg Jost, ${ }^{4}$ Martin Meisenheimer, ${ }^{2}$ Herbert Wachtel $^{2}$

'Department of Medicine, University of Tennessee Graduate School of Medicine, Knoxville, TN 37920, USA; ${ }^{2}$ Boehringer Ingelheim Pharma $\mathrm{GmbH} \& \mathrm{Co}$. KG, Ingelheim am Rhein 55216, Germany; ${ }^{3}$ Boehringer Ingelheim International $\mathrm{GmbH}$, Ingelheim am Rhein 55216, Germany; ${ }^{4}$ Boehringer Ingelheim Pharma, Biberach an der Riss 88397, Germany

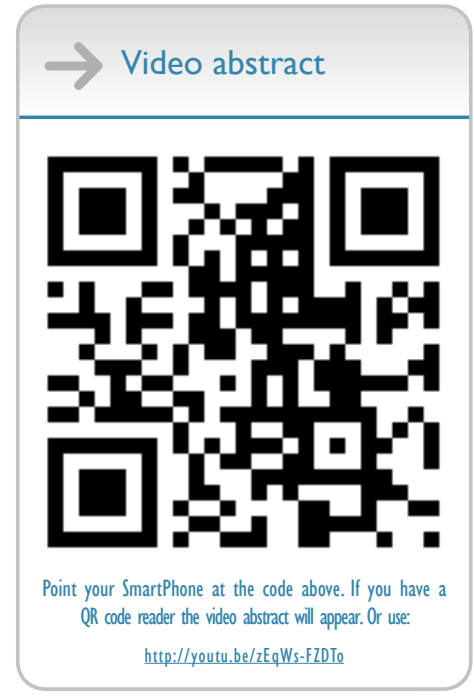

Correspondence: Herbert Wachtel Boehringer Ingelheim Pharma GmbH \& Co. KG, I 73 Binger Strasse, Ingelheim am Rhein 55216, Germany

Tel +496132779 8552

Email herbert.wachtel@boehringeringelheim.com
Purpose: The Respimat is a handheld, propellant-free, soft-mist inhaler. Observations by patients and physicians prompted development of an improved second-generation Respimat inhaler. Human-factor studies assessing the usability of the new inhaler and in vitro assessment of aerosol performance are important to demonstrate functionality of the updated inhaler. Methods: Studies were performed to assess any possible impact of the reusable Respimat inhaler design on aerosol performance (delivered dose [DD] and fine-particle dose [FPD]) and iteratively assess and improve usability of the new design. The tiotropium-olodaterol inhalation solution for Respimat was used as a model. The DD and FPD of the reusable Respimat inhaler (across multiple cartridges) and the disposable Respimat inhaler were determined by laser diffraction and with an alternative Andersen cascade impactor. Usability was measured across three studies involving health care professionals and patients with diagnoses of COPD, asthma, or combined disease (with and without experience with the Respimat inhaler). These studies measured performance of handling tasks and collected subjective feedback directly related to the inhaler's new or altered features, which fed into optimization of the inhaler.

Results: DDs of tiotropium and olodaterol were stable up to 15 cartridges and consistently within the upper and lower limits of the disposable Respimat inhaler. The FPD was also found to be batch-consistent over the cartridges and comparable with the reference. The usability of the reusable Respimat inhaler compared with the disposable inhaler was improved in terms of assembly and daily use. Cartridge exchange was rated as intuitive and easy to very easy.

Conclusion: The new reusable Respimat is a medical inhaler developed with enhanced features that meets health care professionals' and patients' needs. Drug delivery across multiple cartridges is not affected by the design. Compared with the original disposable inhaler, the usability of the reusable inhaler has been improved, and cartridge exchange was rated as easy to perform. The reusable Respimat provides greater convenience for patients vs the disposable inhaler, with reduced environmental impact.

Keywords: inhalers, soft mist, SMI, handling, environment

\section{Plain language summary}

Patients and doctors would like a Respimat inhaler that can be reused with more than one cartridge. The disposable Respimat inhaler has been updated to allow it to be reusable and improve its ease of use. These studies show that delivery of the drug from the reusable inhaler is similar to the disposable inhaler. People prefer the new features of the reusable inhaler and find it easier to use than the disposable one. The changes to the Respimat inhaler mean it can be reused with six cartridges. 


\section{Introduction}

The Respimat Soft Mist inhaler is a handheld, propellantfree device that produces a slow-moving, long-lasting mist of drug for inhalation. ${ }^{1}$ It offers the benefits of generating an inhalable aerosol plume that features a high fine-particle fraction independently of the inspiratory airflow, with optimal aerosol velocity and generation time. This results in ease of inhalation and higher lung deposition of drug compared with dry-powder inhalers or pressurized metereddose inhalers. ${ }^{1}$ The inhaler has been available in different regions and in different formats since 2004 as Spiriva (tiotropium), Spiolto (tiotropium-olodaterol), Striverdi (olodaterol), Berodual (ipratropium-fenoterol hydrobromide), and Combivent (albuterol-ipratropium) Respimat for treatment of patients with COPD or asthma. Having gained wide use ( $>10$ million patient-years across all products), the Respimat inhaler is well accepted and has a high satisfaction rate among patients, ${ }^{2}$ potentially supporting treatment compliance. ${ }^{3}$ As a result of the slow speed and prolonged duration of the soft mist produced by the Respimat inhaler, there is reduced oropharyngeal deposition and increased lung deposition. ${ }^{4,5}$ Because of its higher efficiency of drug delivery, lower nominal doses are required for patients, offering better control of symptoms and increased therapeutic ratio. ${ }^{6}$ Therefore, it is important that the high efficiency of drug delivery and dosing consistency should be preserved with any updates to the inhaler.

With the cartridge inserted, the Respimat inhaler generates an aerosol of medication. Once the labeled number of doses has been reached, the inhaler locks, ie, the inhaler can be used with one cartridge only and is thus "disposable". As a result, a new inhaler is required. Physicians and patients have indicated that they would prefer an inhaler with simplified handling that can be used with more than one cartridge. Consequently, the Respimat inhaler has been updated to simplify assembly and daily use, optimize the dose indicator, and make it reusable, with up to six cartridges with an intuitive cartridge-exchange mechanism. The updated design is intended to improve the usability and environmental impact of the Respimat inhaler, while preserving the pharmaceutical performance and basic functions of the disposable Respimat inhaler. The aim of this article is to outline the changes and improvements made to the Respimat inhaler that enable it to be reusable, and to report data from studies investigating the pharmaceutical performance (delivered dose [DD] and fine-particle dose [FPD]) and usability of the reusable Respimat inhaler.

\section{Methods}

\section{Function and design of the reusable Respimat inhaler}

To fulfill the design target of improving usability, based on usability feedback, and allow the inhaler to be reusable, challenges had to be addressed:

- moving the dose indicator to be attached to the cartridge, rather than part of the inhaler

- ensuring that the previous device lock was reversible if a new cartridge was inserted

- maintaining a cartridge lock that prevents use of the cartridge after the labeled number of doses and prevents use of an empty cartridge

- providing a memory aid to monitor the end of device

- utilizing usability feedback to iteratively improve the handling of the inhaler.

Key characteristics that remain unchanged in the development of the reusable Respimat inhaler included the main design and appearance, basic handling steps for priming and daily use (although the instructions for use have been simplified), and the metering and release of the soft mist. In addition, materials and parts that are in contact with the inhalation solution, the cartridge itself, the number of actuations per cartridge, and the corresponding in-use period were retained.

\section{Performance of the reusable Respimat inhaler}

It is important that updates to the inhaler do not impact the approved performance or drug delivery of the Respimat Soft Mist inhaler. Therefore, a series of investigations were carried out to ensure that the drug delivery was comparable between the disposable and reusable inhalers and that reuse with several cartridges did not affect drug delivery.

Development was performed for three of the Respimat products: Spiriva (tiotropium $5 \mu \mathrm{g}$ ), Striverdi (olodaterol $5 \mu \mathrm{g}$ ), and the combination product, Spiolto (tiotropiumolodaterol, $5 \mu \mathrm{g}$ each). As there is no relevant difference in physicochemical properties between the formulations of tiotropium and/or olodaterol used in Respimat inhalers due to their comparable composition, studies used the tiotropium-olodaterol (5 $\mu \mathrm{g}$ each) combination-inhalation solution as the model solution. The DD and FPD were each tested in a series of studies, with cartridges from the reusable Respimat inhaler compared with a reference from a disposable Respimat inhaler. Initially, for the intended use of six cartridges, the consistency and robustness of the 
dosing of the reusable Respimat inhaler were tested over nine cartridges (ie, 1.5 times the intended number of actuations) in ten inhalers, so as to be in accordance with the requirement of the International Organization for Standardization (ISO) standard for "claimed lifetime testing" (ISO 20072). Further studies also tested use over eleven cartridges and separately over nine cartridges, covering the maximum use period of 27 months (nine cartridges $\times$ the maximum 3 -month in-use time per cartridge). This nine-cartridge study was followed in a continuation study using the same inhalers reactivated after not being used for a 12-month period: this involved a further six cartridges to cover a total of 15 cartridges for a total study duration of 40 months. FPD was determined by laser diffraction and with an Andersen cascade impactor as an alternative method for confirmation, as described previously. ${ }^{8,9}$

\section{Effect of cleaning}

The recommended cleaning period and instructions (clean the mouthpiece at least once per week with a damp cloth) are unchanged with the reusable device. Nevertheless, to support the cleaning instructions included in the patients' instruction for use, an in-use study using Respimat inhalers over six cartridges of tiotropium-olodaterol inhalation solution (one dose per day) was also carried out. Two cleaning frequencies were examined: once a week and none at all. The tiotropium-olodaterol reusable Respimat inhaler was primed, and then two actuations were delivered each day for 30 days. Delivered volume (DV) was determined for actuation numbers 13 and 14, 27 and 28, 41 and 42, and 55 and 56 on cartridges 1,3 , and 6. DD was measured for doses 7, 14, 21, and 28. Particle-size distributions were measured with the laser-diffraction method for actuation numbers 11 and 12, 25 and 26, 39 and 40, and 53 and 54.

\section{Usability}

Boehringer Ingelheim retained UL-Wiklund and Perleberg Pharma Partner to conduct two formative tests and one summative usability test. Based on the formative tests, the inhaler was improved iteratively to address users' feedback, simplify handling, optimize readability of the dose indicator, and allow for reuse of the inhaler.

Human-factor usability studies were performed in Germany, the Netherlands, Spain, and Brazil, and involved patients (aged 8-75 years) with diagnoses of COPD, asthma, or combined disease (with and without experience with the Respimat inhaler) and health care professionals (HCPs).
Study participants performed handling tasks with the disposable and reusable Respimat inhalers. Tasks were developed to include all necessary handling steps for using the inhaler and were organized to simulate a natural workflow. Tasks included assembling the inhaler, delivering a daily dose of placebo medication (simulated use), identifying when the cartridge was empty and replacing it, and interpreting the inhaler's end-of-use status. The first test evaluated the reusable inhaler's general handling and ease of use. The test administrator directed each participant to perform seven tasks:

- task 1 - familiarize themselves with the starter-pack carton containing a reusable Respimat inhaler, cartridge, and instructions for use, for as long as needed

- task 2 - assemble the inhaler and simulate administering a dose

- task 3-describe the status, function, and related actions of three dose-indicator statuses $(60,10$, and 0 puffs remaining)

- task 4 - administer a dose (simulated) with an inhaler containing an empty cartridge

- task 5 - administer a dose (simulated) with a cartridge indicating ten remaining puffs and four already marked check boxes on the inhaler's label

- task 6 - remove a cartridge that still contains doses

- task 7 - evaluate and compare different dose-indicator design concepts, presented as onscreen interactive prototypes.

After participants had completed tasks 2, 4 and 6, the administrator asked them to rate various inhaler handling steps' ease of use on a 7-point Likert scale ( $1=$ difficult, $7=$ easy).

The second test compared the reusable inhaler with the disposable Respimat inhaler. Participants were asked to compare the current disposable Respimat inhaler with the reusable Respimat inhaler. They were asked to give qualitative as well as quantitative feedback on ease or difficulty of use in step-by-step cartridge insertion and assess the dose indicator. They also focused on the cartridge-exchange features of the reusable Respimat inhaler, including assessment and rating of cartridge exchange step by step and the cartridge-label check box to track usage of number of cartridges. Participants used a sliding scale from -7 to +7 to compare both devices directly in regard to each step. Values $<0$ within the scale indicated that the step was easier with the disposable inhaler, 0 indicated that both devices were perceived the same, and values $>0$ indicated the step was easier for the reusable Respimat. For assessments of exchange features of the reusable inhaler, participants were asked to rate statements 
related to the features on a scale of $1-7$, with 7 meaning "applies completely", and 1 meaning "does not apply at all", or on their perceived level of difficulty where 1 meant "very difficult" and 7 meant "very easy".

A summative multicountry study was then performed to ensure that the reusable Respimat, its labeling, and instructions for use could be used safely and effectively. Handling was analyzed by obtaining subjective feedback directly related to the new or updated features of the reusable Respimat inhaler compared with the disposable Respimat inhaler.

Participants did not interact with active medication in any of the usability studies. Participants were provided with prototype Respimat inhalers containing a placebo solution, which does not contain any active medication. Furthermore, participants simulated the inhalation step by aiming the inhaler away from their mouth and describing how they would perform the inhalation during actual use (simulated use).

All procedures performed in studies involving human participants were in accordance with the 1964 Declaration of Helsinki and its later amendments. Ethical researchcommittee approval was not required. Written informed consent was obtained from all participants included in the studies.

\section{Results}

\section{Function and design of the reusable Respimat inhaler}

The main aim was to make the disposable Respimat inhaler reusable. To achieve this, only a few secondary components of the disposable Respimat inhaler had to be modified or added. Table 1 gives an overview of the operating elements and defines the terms used in Figure 1A.

The device lock, previously attached to the inhaler, was adapted to a cartridge lock and a resettable device lock, while the dose indicator was also transferred to the cartridge. The dose indicator was made more prominent and easy to read, and displays the actuations remaining in the cartridge (Figure 1B).

The cartridge lock is triggered by the dose indicator reaching the last actuation, and prevents continued use of a used-up cartridge and use of a locked cartridge. Subsequently, the cartridge lock activates the resettable device lock to prevent further use of the device with this used-up cartridge, opens the safety catch of the clear base, and pushes the clear base off so that the patient gets a clear signal to open the inhaler and exchange the cartridge. The inhaler lock is deactivated only with insertion of a new or not used-up cartridge. The clear base was slightly modified to incorporate and to trigger the dose indicator after each actuation and to accommodate a longer grip for twisting the device.

Tracking the number of cartridges used can be monitored by the patient with a cartridge counter, a simple memory aid in the form of a tick box on the inhaler's back label, which is to be marked after insertion of a new cartridge (Figure 1C). After use with six cartridges, the device should be discarded, which is described in the modified labeling. The reusable Respimat inhaler fulfills the essential requirements

Table I Operating elements of Respimat and reusable Respimat

\begin{tabular}{|c|c|c|c|}
\hline & Intended action/feature & Disposable Respimat & Reusable Respimat \\
\hline Mouthpiece & Fits to patient's mouth & Present & Unchanged \\
\hline Air vents & Entrance of air for inhalation & Present & Unchanged \\
\hline Dose-release button & Triggers delivery of aerosol & Present & Unchanged \\
\hline Cap & Protects mouthpiece against dust & Present & Unchanged \\
\hline Device lock & Limits use within safe (and checked) bounds & Present, nonreversible & $\begin{array}{l}\text { Modified to reversible; new or not used-up } \\
\text { cartridge resets device lock }\end{array}$ \\
\hline Cartridge counter & Monitors end of specified inhaler life span & Not implemented & New, indicates used-up device \\
\hline Cartridge lock & Limits use within safe (and checked) bounds & Not implemented & New, locks device when cartridge is used up \\
\hline Dose indicator & $\begin{array}{l}\text { Indicates remaining number of actuations and } \\
\text { prevents normal use after end of specified } \\
\text { cartridge life span }\end{array}$ & Present on inhaler body & Modified, now present on cartridge \\
\hline Safety catch & Keeps clear base in position & Present & $\begin{array}{l}\text { Modified, releases automatically when } \\
\text { cartridge is locked }\end{array}$ \\
\hline Cartridge & Container for aqueous drug solution & Present & Unchanged, but dose indicator added \\
\hline Clear base & $\begin{array}{l}\text { Grip for cocking inhaler, covers bottom part } \\
\text { of device, provides view on device label and } \\
\text { dose indicator }\end{array}$ & Present & $\begin{array}{l}\text { Modified to receive enlarged dose counter } \\
\text { and triggers dose indicator }\end{array}$ \\
\hline Piercing element & Opens foil in order to vent the cartridge & Present & Integrated inside counter \\
\hline
\end{tabular}




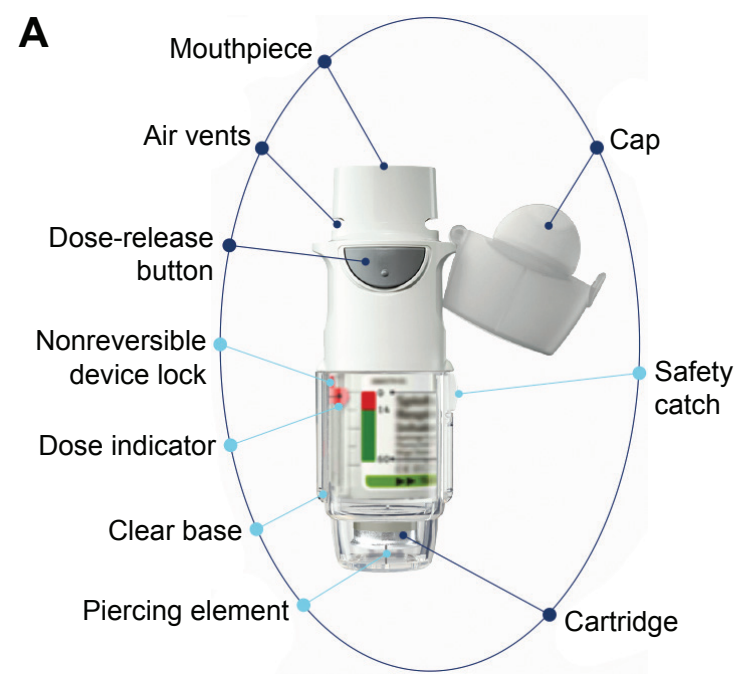

Disposable

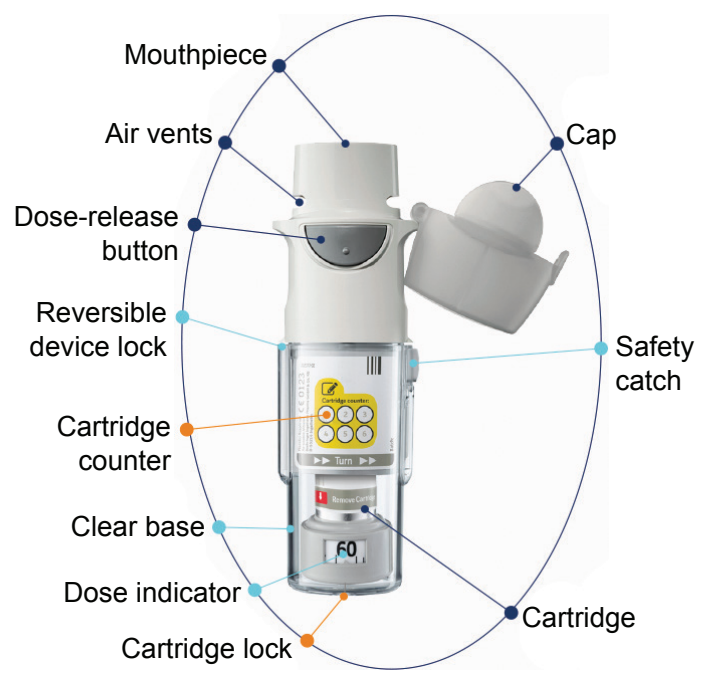

Reusable

Unchanged

Modified

New

B

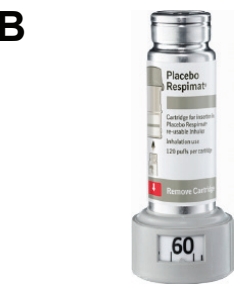

New cartridge 60 actuations remaining
Nearly used up cartridge 10 actuations remaining
Used up cartridge

0 actuations remaining

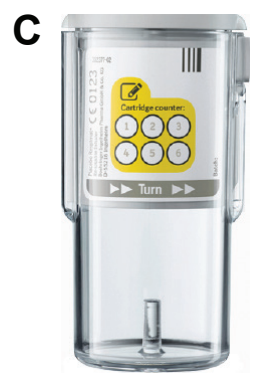

New inhaler

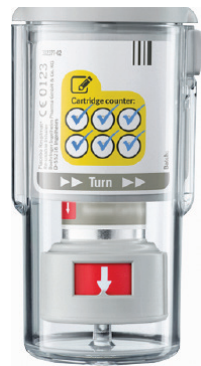

Used up inhaler with 6 cartridges $\rightarrow$ get a new reusable pack

Figure I Respimat design features.

Notes: (A) Disposable vs reusable; (B) dose indicator showing remaining number of actuations; (C) cartridge counter to monitor end of specified inhaler life span.

of the European Union's Medical Device Regulation and the Medical Device Directive 93/42/EWG. The reusable Respimat inhaler is CE-marked (European conformity) as a class IIB device and complies with ISO 20072:2009.?

\section{Performance of the reusable Respimat inhaler}

All three of the Respimat products tested - tiotropium, olodaterol, and tiotropium-olodaterol - showed the same particle-size distribution on laser diffraction (Figure S1A) and the Andersen cascade impactor (Figure S1B) with the reusable inhaler. Both methods provided comparable results. As such, the tiotropium-olodaterol solution was used for all further experiments with the reusable Respimat inhaler.

The tiotropium-olodaterol inhalation solution for Respimat was used as a model solution. The DD was measured by a pharmacopoeial method, and the FPD of both the reusable Respimat inhaler (across multiple cartridges) and the disposable Respimat inhaler were determined by laser diffraction and the alternative Andersen cascade impactor. 
In the first study assessing use across nine cartridges, the DD of the olodaterol (Figure 2A) and of tiotropium (Figure 2B) components with ten reusable inhalers over nine cartridges were both stable and consistently within the upper and lower limits of the reference disposable inhaler.

Further studies also confirmed these data with up to 15 cartridges over a 40-month period, including a 12-month period during which the reusable inhalers were not used and then reactivated with additional new cartridges (Figure S2).
FPD was also shown to be batch-consistent in the reusable inhaler, comparable with the reference disposable inhaler, and stable over the doses up to 15 cartridges (Figure S3).

Particle-size distribution - determined by laser diffractionof one reusable inhaler batch $(n=3)$ used with nine cartridges and with a reference disposable inhaler batch $(n=3)$ was consistent and comparable (Figure 3). Results with the Andersen cascade impactor are shown in Figure 4. In the two figures, the stages of the Andersen cascade impactor
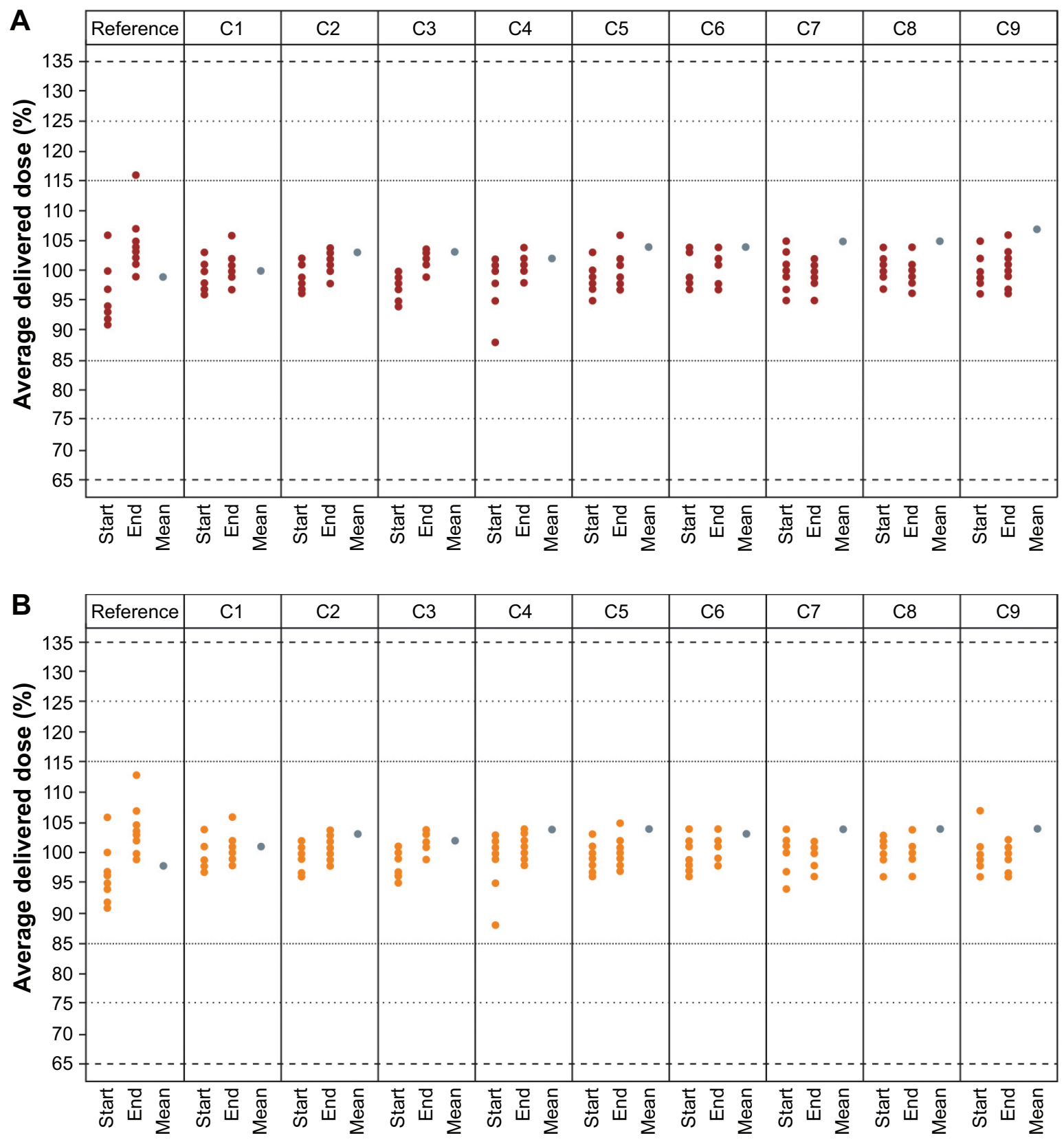

Figure 2 Delivered dose uniformity of $(\mathbf{A})$ olodaterol and $(\mathbf{B})$ tiotropium for nine cartridges in the reusable Respimat.

Notes: The reference disposable Respimat inhaler is shown in the leftmost panel. For each cartridge used in a reusable Respimat, data at start (left row) and end (right row) of cartridge are given. Each colored dot represents mean value for one dose; single gray dots at the right of each cartridge panel represent means of respective cartridge in relation to the label claim. Lines represent 15\% (solid line), 25\% (dots), and 35\% (dashes) deviation from the reference. Mean data from ten inhalers are shown. 


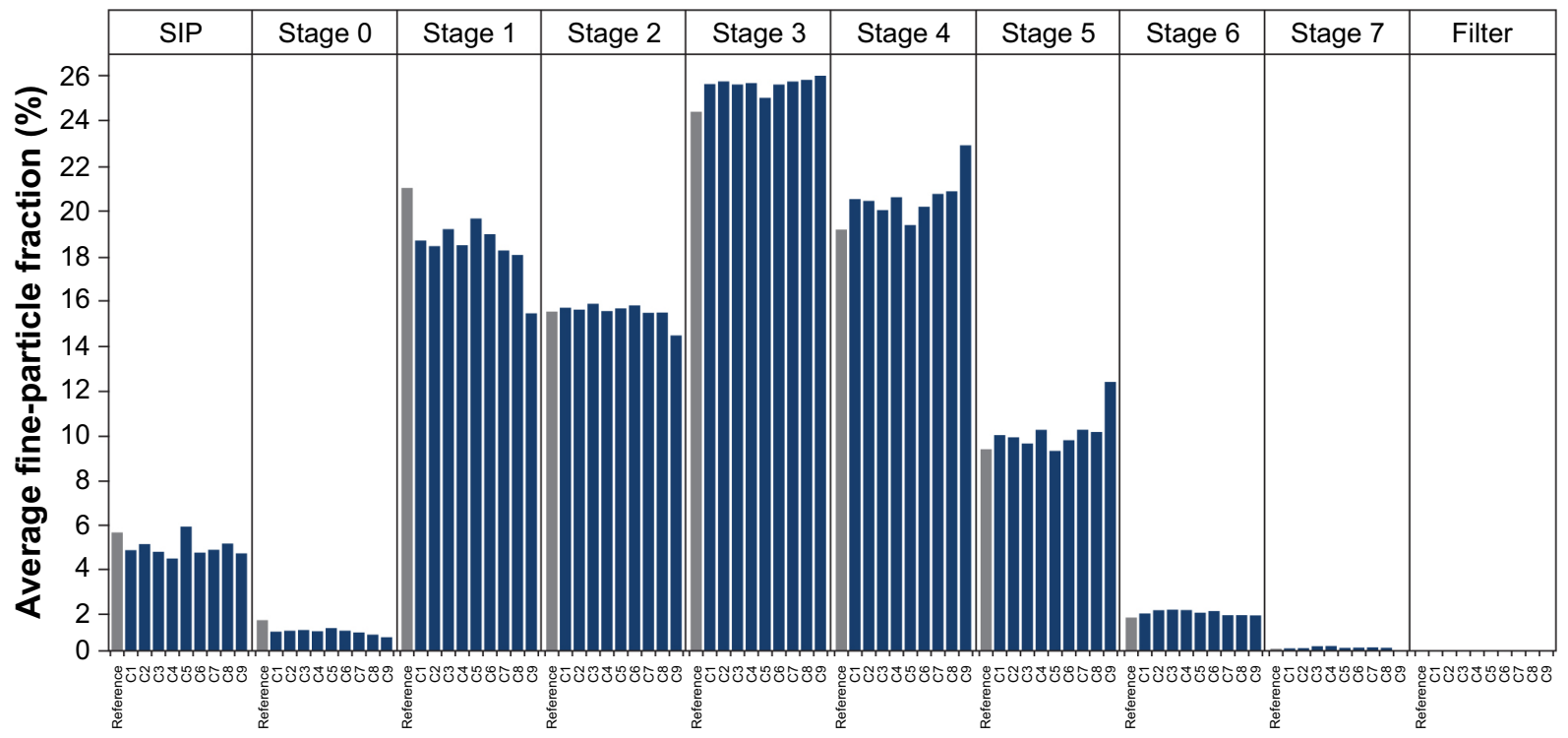

Figure 3 Fine-particle fraction for use of nine cartridges of tiotropium-olodaterol in the reusable Respimat inhaler determined by laser diffraction.

Notes: Gray bars represent a disposable inhaler batch as reference. Dark-blue bars represent the reusable inhaler used with nine cartridges. Mean values for individual inhalers $(n=3)$ are shown. Correlating cutoff sizes of the Andersen cascade impactor were $(\mu \mathrm{m})$ : stage 0 , >9.0; stage I, 9.0-5.8; stage 2, 5.8-4.7; stage 3, 4.7-3.3; stage 4, 3.3-2.I; stage 5, 2.I-I.I; stage 6, I.I-0.7; stage 7, 0.7-0.4; and filter, $<0.4$.

Abbreviation: SIP, sample induction port.

(adapter, sample induction port, plates $1-7$, and filter) are displayed.

\section{Effect of cleaning}

Cleaning frequency was found to have no influence on DV and DD. Figures S4 and S5 show that DV and DD were constant for both cleaning frequencies and over the use of several cartridges in the reusable inhaler. For inhalers that were never cleaned, equivalent particle-size distributions were obtained compared with inhalers that were cleaned weekly. Without cleaning, deposits accumulated on the inner side of the mouthpiece with an increasing number

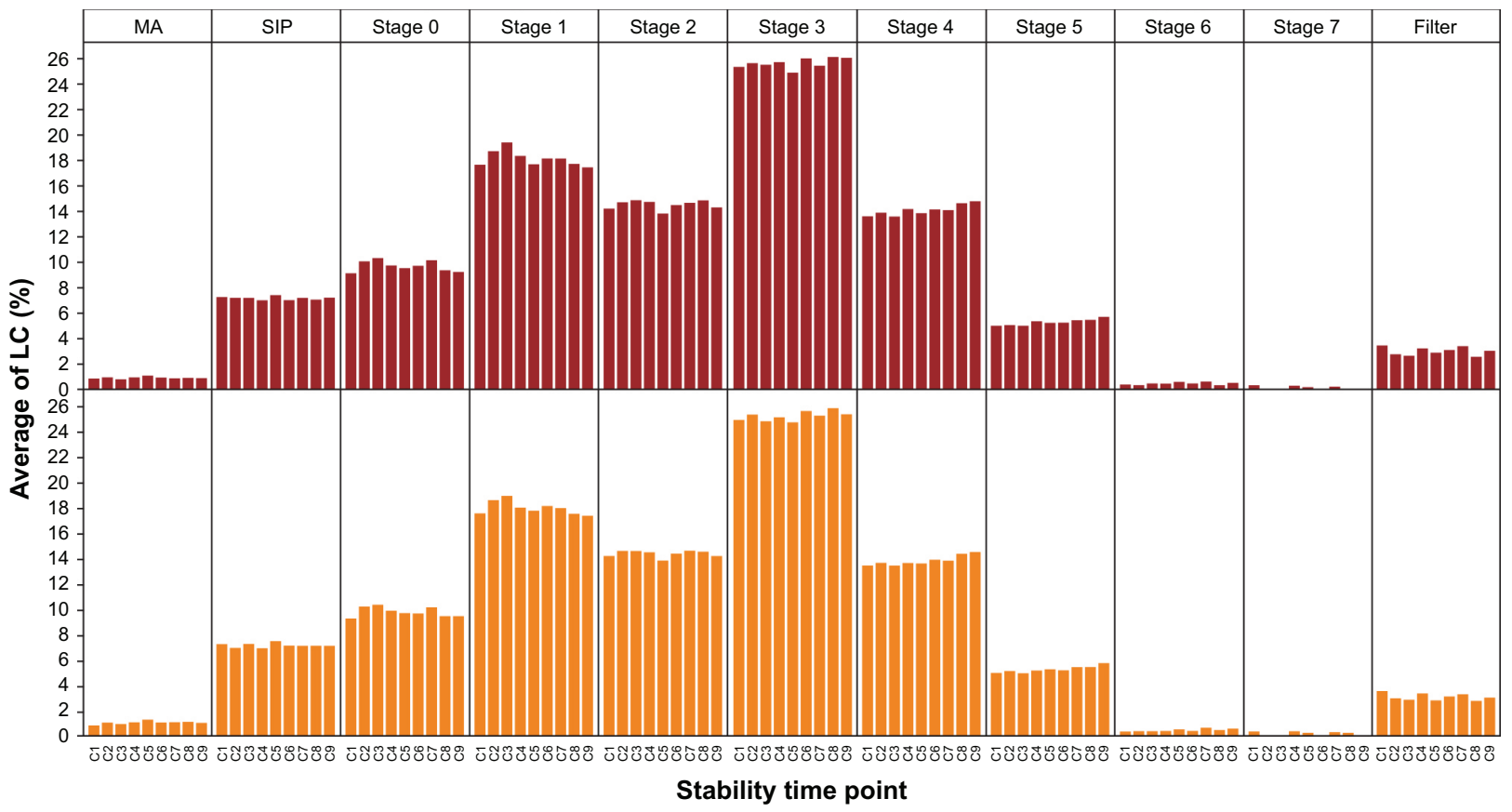

Figure 4 Aerodynamic particle-size distribution for use of nine cartridges of tiotropium-olodaterol in the reusable Respimat inhaler determined by the Andersen cascade impactor. Notes: Olodaterol (top graphic) and tiotropium (bottom graphic). Cutoff sizes of the Andersen cascade impactor were ( $\mu \mathrm{m}$ ): stage 0, >9.0; stage I, 9.0-5.8; stage 2, 5.8-4.7; stage 3, 4.7-3.3; stage 4, 3.3-2.I; stage 5, 2.I-I.I; stage 6, I.I-0.7; stage 7, 0.7-0.4; filter, <0.4. Abbreviations: LC, label claim; MA, mouthpiece adapter; SIP, sample induction port. 


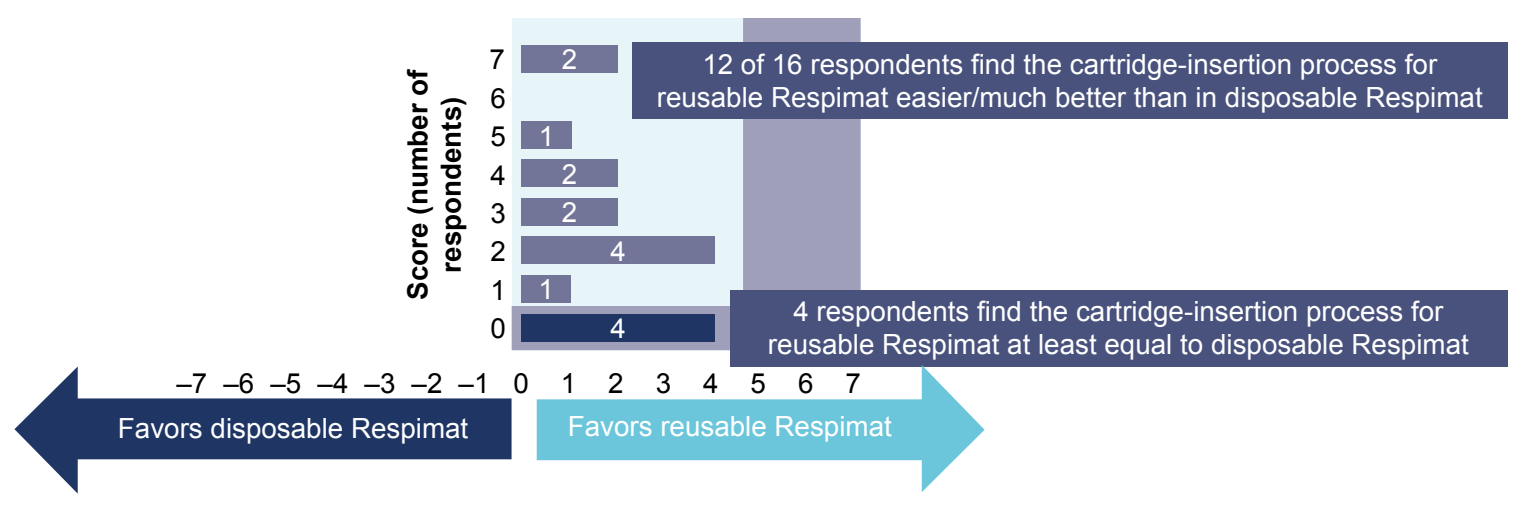

Figure 5 Overall perceived ease of performing cartridge insertion.

Note: Scoring from -7 (favors disposable Respimat) to +7 (favors reusable Respimat).

of cartridges, but did not follow a linear pattern nor influence the reusable inhaler's performance.

\section{Usability}

A total of 65 participants were included across the three studies: eleven HCPs and 54 patients with diagnoses of COPD, asthma, or combined disease; 26 of these patients were Respimat-naïve and 28 had prior experience of using the disposable Respimat inhaler. In the first formative usability test, participants were asked to rate the ease of use regarding the reusable inhaler handling steps on a 7-point Likert scale ( $1=$ difficult, $7=$ easy). Tasks rated easiest to perform were priming the inhaler after inserting a new cartridge (average 6.1), inserting the new cartridge (average 5.7), and identifying the need to replace the cartridge (average 5.5). On average, participants rated removing a cartridge (average 4.6) as most difficult to perform.

In the second formative usability test, involving 16 participants with previous experience with the Respimat inhaler, the majority of participants $(n=13)$ preferred the reusable Respimat over the disposable Respimat inhaler. Each handling step and each cartridge-exchange feature was rated in favor of the reusable Respimat. For example, 12 of 16 respondents gave positive scores related to cartridge insertion and exchange, meaning they considered the cartridge-insertion process to be easier or much easier with the reusable Respimat than the disposable Respimat, while four respondents gave scores of 0 , meaning they felt the process was equally easy in both inhalers (Figure 5). The majority of respondents also considered the reusable Respimat dose indicator to be clearly better than the one in the disposable Respimat inhaler. Average scores (scale 1-7) for "The dose indicator is easily readable" and "It is easy to see how many doses are left" were 6.6 and 5.9, respectively, with the reusable inhaler. Scores related to the clear base-detachment mechanism indicated that it was easy to understand, practical, and intuitive (Figure 6). Finally, regarding the level of ease of exchanging a refill cartridge, participants found all steps to replace a cartridge "easy" to "very easy" (Figure 7). In particular, qualitative feedback from some participants indicated that the modified base of the cartridge and larger clear base facilitated an easy grip when turning or removing the clear base and when removing the cartridge.

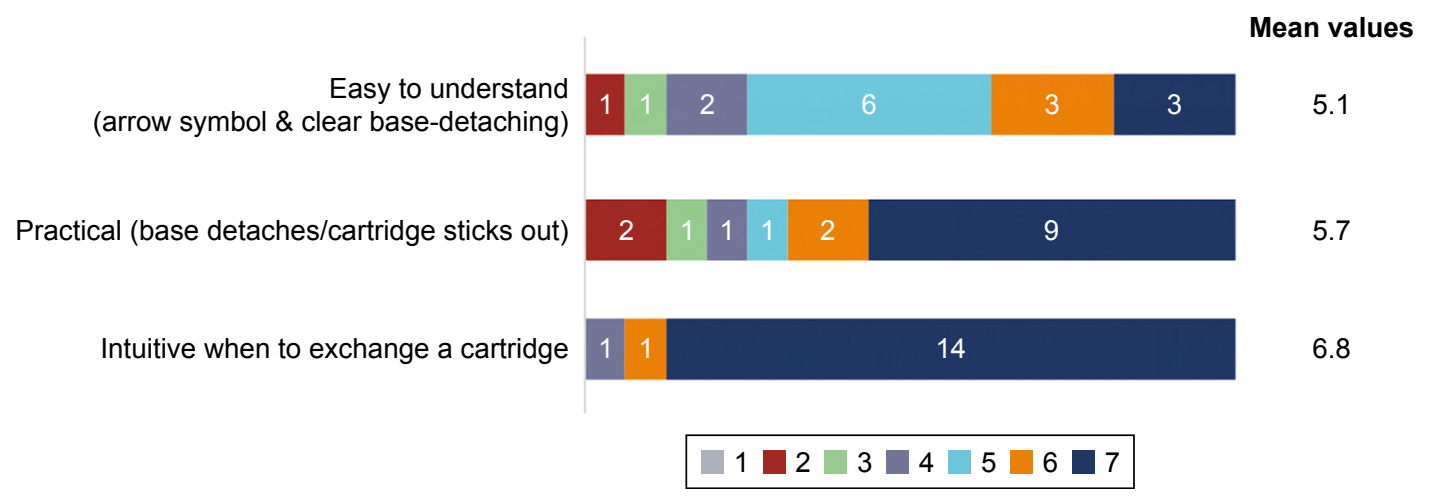

Figure 6 Rating of the clear base-detaching mechanism.

Note: Scoring from I (does not apply at all) to 7 (applies completely). 


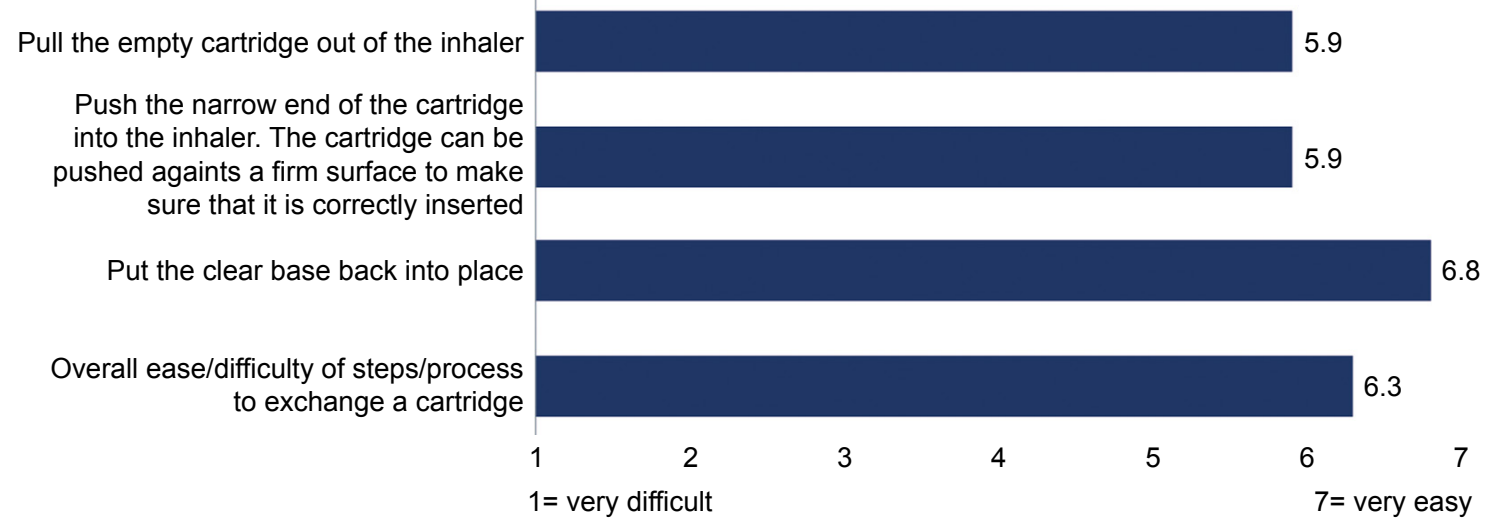

Figure 7 Rating of ease of exchanging a refill cartridge. Note: Scoring from I (very difficult) to 7 (very easy).

The third study, a summative study, conducted with $21 \mathrm{COPD} /$ asthma patients and eleven HCPs, showed all participants were able to carry out the assembly and cartridge replacement and to identify when to replace the cartridge/ inhaler. Subjective feedback from HCPs and patients indicated that the enhanced dose indicator made readability easier and more accurate and the design for exchanging the cartridge was easy. Usability in relation to assembly was improved and seen as a simplification of already learned steps. The main handling difference was the exchange of the cartridge. The lower base can be removed easily and replaced for insertion of a new cartridge, while mechanical lockout prevents reinsertion of a used cartridge.

Overall, test participants considered the reusable inhaler to be a robust device that was at least as easy to use as their current Respimat inhaler, and the inhaler's larger base was felt to be an advantage by some in facilitating an easy grip when turning or removing the clear base. The automatic clear base detachment distinctly indicated when a cartridge needed to be replaced, and insertion of the cartridge was perceived to be comparable or easier by study participants compared with their current Respimat inhaler. Several participants stated that the inhaler's reusability enhanced its user-friendliness, given that they would not need to obtain a new inhaler every month.

\section{Discussion}

The updated reusable Respimat inhaler meets the request from patients and physicians to develop an easy-to-use Respimat inhaler that can be used with more than one cartridge. The reusable inhaler has improved usability, with no effect on efficiency of drug delivery, aerosolparticle size, or required inhalation method across multiplecartridge use.
Performance characteristics of the medications depend on the aerosol design of the Respimat inhaler and the physicochemical properties of the inhalation solutions used. Therefore, great care was taken to maintain consistency in any element of the inhaler that may affect the aerosolization and to ensure that performance characteristics remained constant. Our results indicate that the performance of the reusable Respimat inhaler is comparable to that of the disposable inhaler. Therefore, lung deposition and clinical data established with the disposable inhaler can be transferred to the reusable inhaler. Inhaler-performance data are provided for up to 15 cartridges, well above the intended use of six cartridges, providing reassurance of performance, even if the inhaler is accidentally used beyond the six cartridges.

Previously, little attention has been paid to the role of the inhaler in randomized controlled trials, as they are often assumed to be clinically equivalent in delivering similar inhalation medications. ${ }^{10}$ Several studies have examined patient satisfaction and preferences for specific inhalers, ${ }^{3,11,12}$ although it is acknowledged that these are open to bias. Studies indicate that higher patient satisfaction with their asthma/COPD drug-delivery inhaler is an important factor in treatment adherence and a significant predictor of more favorable clinical outcomes. ${ }^{3,11,13}$ Satisfaction with inhalers is also positively correlated with reduced costs, since good adherence is correlated with reductions in health careresource utilization. ${ }^{13}$ A systematic review of how updates to handheld inhalers, with or without new active substances, impacts on patient preferences also demonstrated that development or updating of inhalers may improve patient satisfaction. ${ }^{10}$ Attributes associated with inhaler satisfaction included patients' perceptions of consistency in ease of use, feedback about the number of remaining doses, durability, ergonomics, and drug DD to the lungs., ${ }^{3,11}$ Patients have 
previously reported high satisfaction rates with both inhaling from and handling the Respimat inhaler. ${ }^{14}$ In clinical studies, the Respimat Soft Mist inhaler has consistently been shown to be well accepted by patients with COPD, largely due to its inhalation and handling characteristics. . $^{2,15,16}$

Many features of the disposable Respimat, its appearance, and basic handling processes have thus been retained in the updated reusable inhaler, and aspects related to the reusability of the device, such as the redesigned locking mechanisms and replacing cartridges, were assessed. Our usability tests demonstrated that the reusable Respimat compared favorably with the original disposable inhaler in many aspects of handling and ease of use. The reusable Respimat inhaler is prepared for use and used daily in the same way as a disposable Respimat; however, such improvements as the dose indicator (which has been made easier to read), easier release of the clear base, and easier cartridge removal and insertion have improved the usability of the inhaler and may provide greater convenience for patients vs the disposable inhaler. The slightly increased size of the inhaler also facilitated better grip with some patients.

There are also clearly environmental benefits of reusable inhalers. A variety of inhalers are currently available to patients with asthma or COPD, and there are several schemes to enable patients to recycle inhalers by returning used units to pharmacies that have signed up to the scheme. A recent study showed that the reusable Respimat inhaler can reduce the already low product carbon footprint of the disposable inhaler by $71 \%$ if supplied with six cartridges. ${ }^{17,18}$ By developing reusable inhalers, there appear to be clear environmental gains without change in performance.

Evidently, there may be some limitations to these studies. There were a limited number of patients and HCPs involved, and some of the feedback was of a subjective nature. We have compared only the updated reusable inhaler with the disposable inhaler, and further studies comparing the reusable inhaler with other inhalers would be of interest.

\section{Conclusion}

The reusable Respimat Soft Mist inhaler includes enhanced features that simplify its assembly and improve handling and ease of use. Performance in terms of DD and FPD remains unchanged compared with the disposable Respimat. The excellent stability of the reusable Respimat inhaler was confirmed, with batch-to-batch variability that was minimal and remained within the reference limits, even when used for 15 cartridges. The usability of the reusable Respimat inhaler compared with the original disposable inhaler has been improved in terms of handling and ease of use. Moreover, cartridge exchange was rated as intuitive and simple to manage. It has a reduced environmental impact vs the disposable inhaler. Patients can be reassured that their treatment quality is maintained with the updated reusable Respimat inhaler.

\section{Data sharing statement}

All authors had full access to all data in these studies and take complete responsibility for the integrity of the data and accuracy of the data analysis. Data are available on request.

\section{Acknowledgments}

Sponsorship for this study and article processing charges were funded by Boehringer Ingelheim. Editorial assistance in the preparation of this article was provided by Dr Victoria Kinsley of SciMentum (a Nucleus Global company, UK). Support for this assistance was funded by Boehringer Ingelheim. We would like to thank participants for their contribution to this study.

\section{Author contributions}

All authors contributed to data analysis, drafting or revising the article, gave final approval of the version to be published, and agree to be accountable for all aspects of the work.

\section{Disclosure}

$\mathrm{RD}$ has received speaker fees from Sunovion, participated in advisory boards for Bayer (Leverkusen, Germany), AstraZeneca (Cambridge, UK), and GlaxoSmithKline (Brentford, UK), and received honoraria from Sunovion (Marlborough, MA, USA), Bayer, and UpToDate (Waltham, MA, USA). IJ, MM, and HW are employees of Boehringer Ingelheim. JE and $\mathrm{MH}$ were employees of Boehringer Ingelheim at the time of the study. All authors report no other conflicts of interest in this work.

\section{References}

1. Dalby RN, Eicher J, Zierenberg B. Development of Respimat ${ }^{(\circledast)}$ Soft Mist ${ }^{\mathrm{TM}}$ inhaler and its clinical utility in respiratory disorders. Med Devices. 2011;4:145-155.

2. Schürmann W, Schmidtmann S, Moroni P, Massey D, Qidan M. Respimat Soft Mist inhaler versus hydrofluoroalkane metered dose inhaler: patient preference and satisfaction. Treat Respir Med. 2005;4(1):53-61.

3. Chrystyn H, Small M, Milligan G, Higgins V, Gil EG, Estruch J. Impact of patients' satisfaction with their inhalers on treatment compliance and health status in COPD. Respir Med. 2014;108(2):358-365.

4. Hochrainer D, Hölz H, Kreher C, Scaffidi L, Spallek M, Wachtel H. Comparison of the aerosol velocity and spray duration of Respimat Soft Mist inhaler and pressurized metered dose inhalers. J Aerosol Med. 2005; 18(3):273-282.

5. Newman SP, Steed KP, Reader SJ, Hooper G, Zierenberg B. Efficient delivery to the lungs of flunisolide aerosol from a new portable hand-held multidose nebulizer. J Pharm Sci. 1996;85(9):960-964. 
6. Caillaud D, Le Merre C, Martinat Y, Aguilaniu B, Pavia D. A doseranging study of tiotropium delivered via Respimat Soft Mist inhaler or HandiHaler in COPD patients. Int J Chron Obstruct Pulmon Dis. 2007; 2(4):559-565.

7. International Organization for Standardization. ISO 20072:2009 aerosol drug delivery device design verification - requirements and test methods. Available from: https://www.iso.org/standard/41989.html. Accessed May 25, 2018

8. Ziegler J, Wachtel H. Comparison of cascade impaction and laser diffraction for particle size distribution measurements. J Aerosol Med. 2005; 18(3):311-324.

9. Wachtel H, Ziegler J. Improved assessment of inhaler device performance using laser diffraction. Respir Drug Deliv. 2002;2:379-382.

10. Ninane V, Vandevoorde J, Cataldo D, et al. New developments in inhaler devices within pharmaceutical companies: a systematic review of the impact on clinical outcomes and patient preferences. Respir Med. 2015;109(11):1430-1438.

11. Price D, Harrow B, Small M, Pike J, Higgins V. Establishing the relationship of inhaler satisfaction, treatment adherence, and patient outcomes: a prospective, real-world, cross-sectional survey of US adult asthma patients and physicians. World Allergy Organ J. 2015;8(1):26.

12. Gálffy G, Mezei G, Németh G, et al. Inhaler competence and patient satisfaction with Easyhaler ${ }^{\mathbb{R}}$ : results of two real-life multicentre studies in asthma and COPD. Drugs R D. 2013;13(3):215-222.
13. Mäkelä MJ, Backer V, Hedegaard M, Larsson K. Adherence to inhaled therapies, health outcomes and costs in patients with asthma and COPD. Respir Med. 2013;107(10):1481-1490.

14. Valipour A, Tamm M, Kociánová J, Bayer Zubek V, Medvedchikov A, Haaksma Herczegh M, et al. Improvement of self-reported physical functioning with tiotropium/olodaterol in Central and Eastern European COPD patients. Eur Respir J. 2018;52 (Suppl 62):PA912.

15. Hodder R, Price D. Patient preferences for inhaler devices in chronic obstructive pulmonary disease: experience with Respimat Soft Mist inhaler. Int J Chron Obstruct Pulmon Dis. 2009;4:381-390.

16. Dal Negro RW, Povero M. Acceptability and preference of three inhalation devices assessed by the handling questionnaire in asthma and COPD patients. Multidiscip Respir Med. 2016;11(1):7.

17. Haensel M, Bambach T, Wachtel H. A comparison of product carbon footprints of Respimat ${ }^{\circledR}$ versus pressurized metered dose inhalers. Respir Drug Deliv. 2018;2:321-324.

18. Haensel M, Bambach T, Wachtel H. Reduced environmental impact of a reusable soft mist inhaler. Eur Respir J. 2018;52(Supplement 62):PA1021. 


\section{Supplementary materials Usability}

Formative usability test I

In 2014, UL-Wiklund conducted a formative usability test of the reusable Respimat inhaler. The test's primary purpose was to evaluate the inhaler's general handling and ease of use. The test was conducted in Utrecht, the Netherlands and São Paulo, Brazil. Seventeen adult patient participants participated in the formative usability test. All participants had experience using an inhaler to treat their respiratory illness (ie, COPD, chronic bronchitis, and/or asthma): five participants had prior experience with a disposable Respimat inhaler, and 12 had experience with inhalers other than a Respimat. During a 2-hour one-to-one session, the test administrators (two) directed each participant to perform the requested tasks. In Brazil, an interpreter provided real-time translation. All data were recorded directly into a customized Excel spreadsheet.

\section{Formative usability test 2}

Perleberg Pharma Partner conducted the second formative usability test of the reusable Respimat inhaler in Germany, in which they compared the reusable inhaler to the disposable Respimat inhaler. Sixteen adult patients participated in one-to-one discussions as part of formative usability test 2 . All participants had experience using a disposable Respimat inhaler to treat their respiratory illness (ie, COPD, chronic bronchitis, and/or asthma): nine participants had experience using a disposable Respimat inhaler for $1-3$ months, and
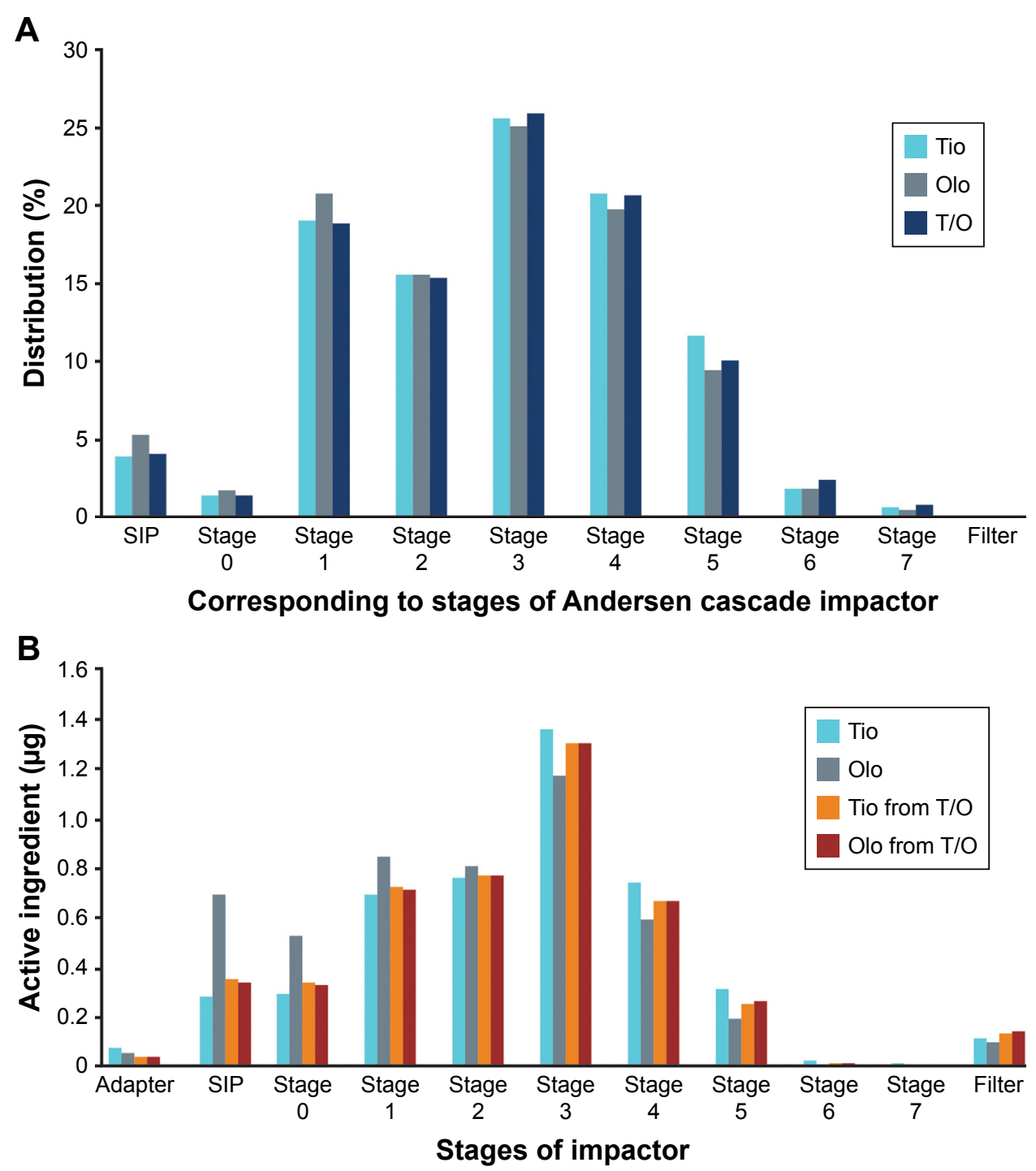

Figure SI Particle-size distributions of tiotropium, olodaterol, and tiotropium-olodaterol by (A) laser diffraction and (B) Andersen cascade impactor.

Notes: Data are means of stability batches. For tiotropium-olodaterol Respimat, the particle-size distribution of tiotropium and olodaterol is shown. Correlating cutoff sizes of the Andersen cascade impactor were $(\mu \mathrm{m})$ : stage 0 , >9.0; stage I, 9.0-5.8; stage 2, 5.8-4.7; stage 3, 4.7-3.3; stage 4, 3.3-2.I; stage 5, 2.I-I.I; stage 6, I.I-0.7; stage 7, 0.7-0.4; and filter, $<0.4$.

Abbreviations: Olo, olodaterol; SIP, sample induction port; T/O, tiotropium-olodaterol; Tio, tiotropium. 

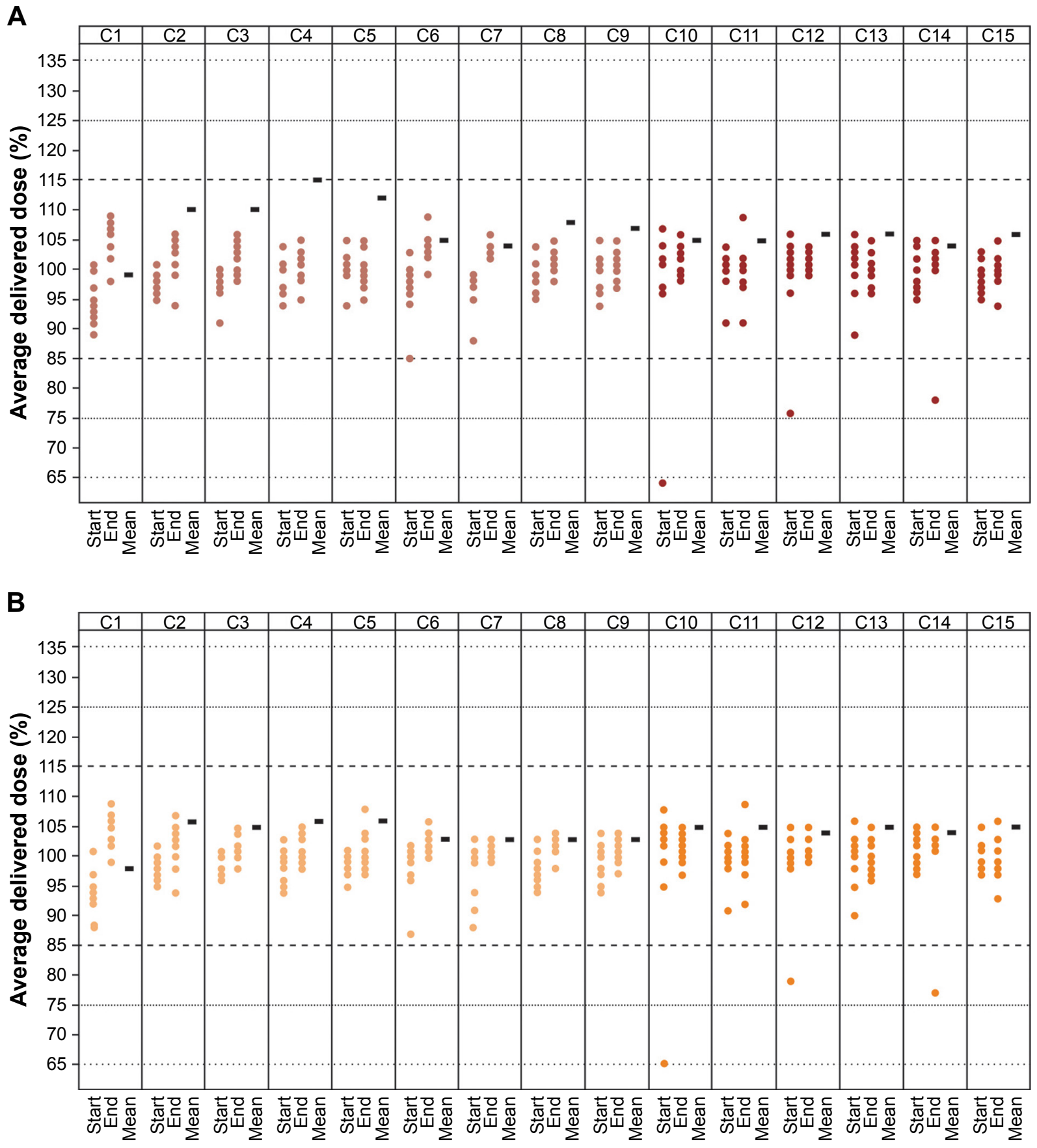

Figure S2 Delivered dose uniformity of $(\mathbf{A})$ olodaterol and $(\mathbf{B})$ tiotropium within reusable tiotropium-olodaterol Respimat for 15 cartridges.

Notes: Lighter columns, cartridges I-9 (in-use testing); darker columns, cartridges 10-15 (sequential testing after 12 months' nonuse). For each cartridge, the individual values at the start and the end of the testing schedule are given as a percentage referring to the average of all individual values, and the mean value is given as a percentage referring to the target dose.

seven participants had experience using a disposable Respimat inhaler for at least 6 months.

\section{Summative usability study}

UL-Wiklund conducted this multicountry usabilityconfirmation test in Brazil, the Netherlands, and Spain between March 29 and April 12, 2016. A total of 32 participants
(21 patients with COPD and/or asthma and eleven health care professionals) completed 90-minute individual sessions. Two-person teams worked to administer the test sessions and record test data. In Spain and Brazil, an interpreter was present in the room to provide real-time translation of the conversations between administrator and participant. All participants had prior experience using inhalation devices, 


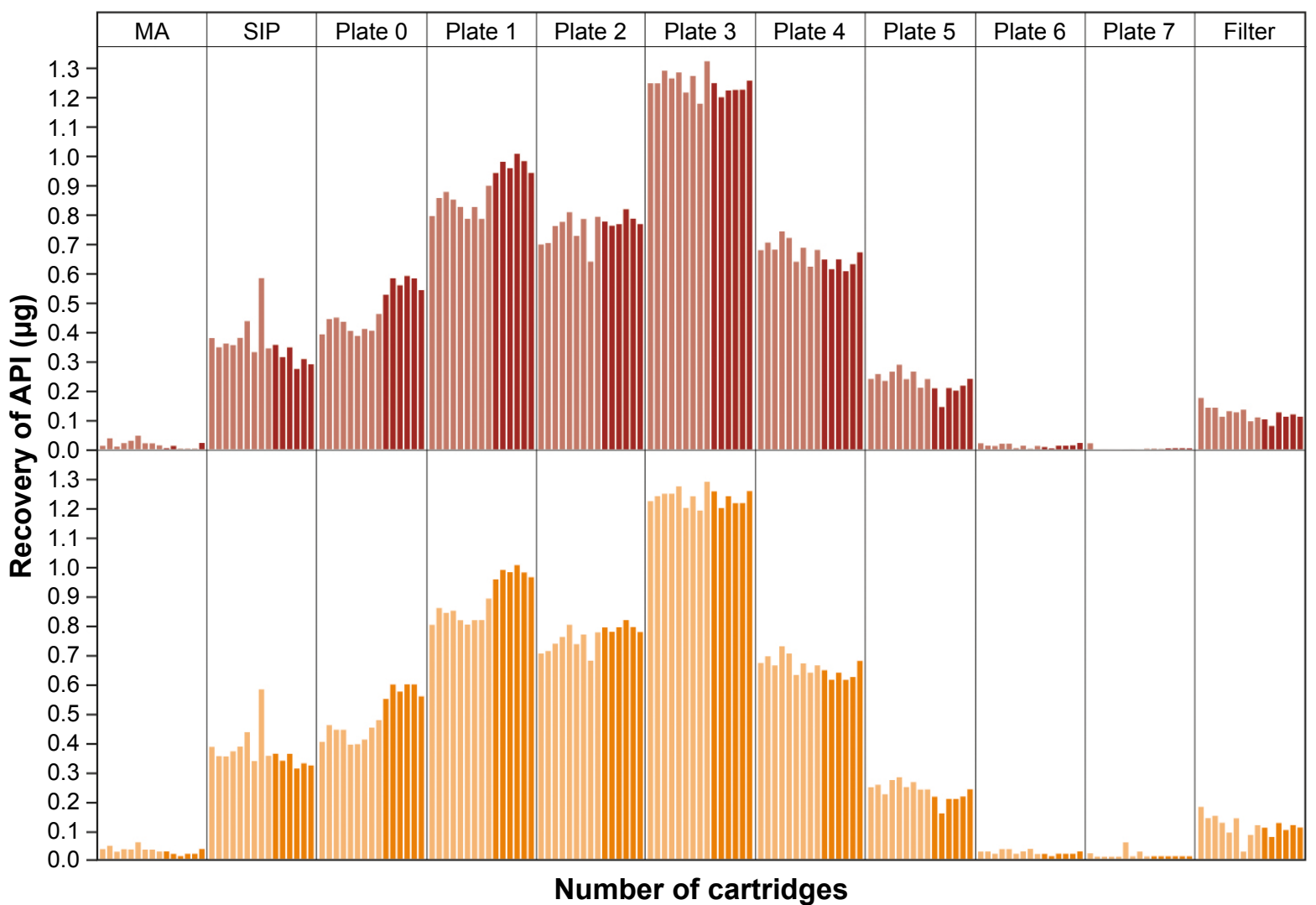

Figure S3 Particle-size distribution (Andersen cascade impactor) of tiotropium-olodaterol reusable Respimat for 15 cartridges.

Notes: Lighter columns, cartridges 1-9; darker columns, cartridges 10-15; upper panel, olodaterol; lower panel, tiotropium. Cutoff sizes of the Andersen cascade impactor were $(\mu \mathrm{m})$ : stage 0 , >9.0; stage I, 9.0-5.8; stage 2, 5.8-4.7; stage 3, 4.7-3.3; stage 4, 3.3-2.I; stage 5, 2.I-I.I; stage 6, I.I-0.7; stage 7, 0.7-0.4; and filter, <0.4.

Abbreviations: API, active pharmaceutical ingredient; MA, mouthpiece adapter; SIP, sample induction port.

and seven had prior experience using a disposable Respimat inhaler. The test administrator introduced the participant to the test environment and staff, explained the test purpose, and asked background questions. Subsequently, participants performed the series of hands-on tasks. After completion of each task and all tasks, follow-up questions were asked to debrief on observed usability issues and collect participants' subjective feedback regarding the inhalers.

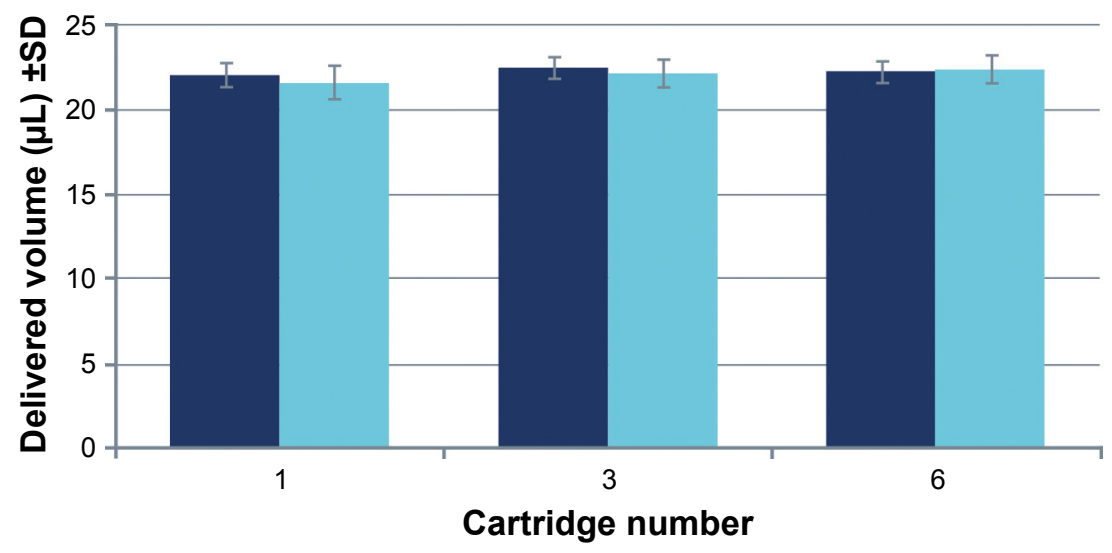

- Cleaning once a week No cleaning

Figure S4 Effect of cleaning frequency on delivered volume of tiotropium-olodaterol.

Notes: Mean values of nine Respimat inhalers of three batches; error bars = relative SD. 

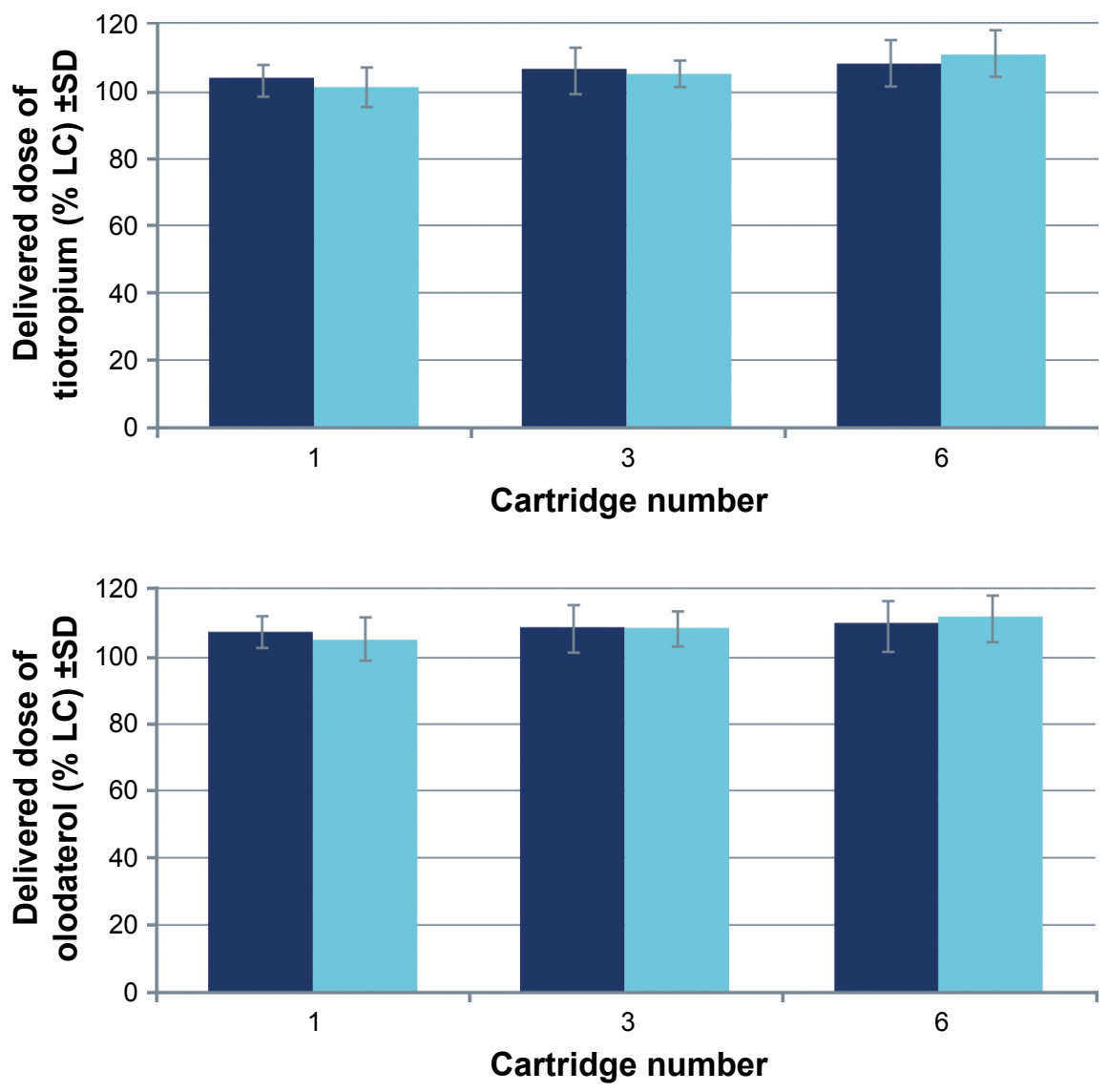

Cleaning once a week No cleaning

Figure S5 Effect of cleaning frequency on delivered dose of tiotropium-olodaterol.

Notes: Mean values of nine Respimat inhalers of three batches; error bars = relative SD.

Abbreviation: LC, label claim.

\section{Publish your work in this journal}

The International Journal of COPD is an international, peer-reviewed journal of therapeutics and pharmacology focusing on concise rapid reporting of clinical studies and reviews in COPD. Special focus is given to the pathophysiological processes underlying the disease, intervention programs, patient focused education, and self management protocols
This journal is indexed on PubMed Central, MedLine and CAS. The manuscript management system is completely online and includes a very quick and fair peer-review system, which is all easy to use. Visit http://www.dovepress.com/testimonials.php to read real quotes from published authors. 